Article

\title{
Sustainable Aromatic Aliphatic Polyesters and Polyurethanes Prepared from Vanillin-Derived Diols via Green Catalysis
}

\author{
Changbo Zhao ${ }^{1}$, Caijuan Huang ${ }^{1, *}$, Qin Chen ${ }^{1}$, Ian D. V. Ingram ${ }^{2}$, Xiankui Zeng ${ }^{1}$, \\ Tianhua Ren ${ }^{1}$ and Haibo Xie ${ }^{1, *}$ \\ 1 Department of Polymer Materials \&Engineering, College of Materials \& Metallurgy, Guizhou University, \\ West Campus, Huaxi District, Guiyang 550025, China; zcb565782908@163.com (C.Z.); \\ qchen6@gzu.edu.cn (Q.C.); xk_kkkkk@163.com (X.Z.); thren96@outlook.com (T.R.) \\ 2 Department of Natural Sciences, Manchester Metropolitan University, Chester Street, Manchester M1 5DG, \\ UK; i.ingram@mmu.ac.uk \\ * Correspondence: cjhuang98@163.com (C.H.); hbxie@gzu.edu.cn (H.X.); Tel.: +86-851-83627806 (H.X.)
}

Received: 30 October 2019; Accepted: 7 February 2020; Published: 5 March 2020

\begin{abstract}
The design and preparation of polymers by using biobased chemicals is regarded as an important strategy towards a sustainable polymer chemistry. Herein, two aromatic diols, 4-(hydroxymethyl)-2-methoxyphenol and 2-(4-(hydroxymethyl)-2-methoxyphenoxy)ethanol, have been prepared in good yields through the direct reduction of vanillin and hydroxyethylated vanillin (4-(2-hydroxyethoxy)-3-methoxybenzaldehyde) using $\mathrm{NaBH}_{4}$, respectively. The diols were submitted to traditional polycondensation and polyaddition with acyl chlorides and diisocyanatos, and serials of new polyesters and polyurethanes were prepared in high yields with moderate molecular weight ranging from 17,000 to $40,000 \mathrm{~g} \mathrm{~mol}^{-1}$. Their structures were characterized by ${ }^{1} \mathrm{H} \mathrm{NMR},{ }^{13} \mathrm{C} \mathrm{NMR}$ and FTIR, and their thermal properties were studied by TGA and differential scanning calorimetry (DSC), indicating that the as-prepared polyesters and polyurethanes have $\mathrm{T}_{\mathrm{g}}$ in the range of 16.2 to $81.2^{\circ} \mathrm{C}$ and 11.6 to $80.4{ }^{\circ} \mathrm{C}$, respectively.
\end{abstract}

Keywords: lignin; vanillin; green catalysis; full bio-based polyesters; polyurethane

\section{Introduction}

With the continuous exploitation of petroleum-based resources, energy and materials, humanity faces serious challenges in terms of both climate change and the availability of useable resources [1]. In particular, the use and disposal of non-degradable plastics in our daily lives leads to serious microplastic particle accumulation and pollution in both soil and aquatic environments [2]. Therefore, it is of great importance to develop more sustainable polymer materials using renewable resources and green chemistry technologies [3].

Lignocellulosic biomass is the most abundant biomass resources on the planet with more than 75 billion tons available per year [4], and the use of them to produce energy, chemicals and materials is anticipated to reduce our dependence on fossil resources, contributing to development of bio-economy $[5,6]$. Lignocellulosic biomass is composed of cellulose, hemicelluloses and lignin, in which lignin is mainly composed of aromatic units and is the most abundant natural aromatic hydrocarbon on earth $[7,8]$. In recent years, there has been significant interest in the catalytic conversion of lignocellulose to bio-based platform molecules $[9,10]$. For example, cellulose can be converted to methanol, ethanol, ethylene glycol, glucose and 5-hydroxymethylfurfural [11]. A variety of aromatic chemicals can be obtained by catalytic conversion of lignin, including eugenol, vanillin, p-hydroxybenzaldehyde and terephthalic acid [1,12]. Traditionally, vanillin is one of the most important 
perfume compounds in foods, beverages, perfumes and pharmaceuticals and is originally isolated from vanilla plants $[13,14]$. Vanillin can also be produced by various biotechnological approaches and catalytic conversion of lignin, for example, using lignin-derived ferulic acid and glucose as substrates for fermentation with bacteria, fungi or yeasts [13]. Given its useful structural features and the potential for its large-scale production from lignin, vanillin is considered to be a promising bio-based building block chemical for the preparation of sustainable aromatic polymers $[15,16]$. Vanillin derivatives with desirable functionalities for polymer synthesis can be obtained through carboxylation, hydroxylation, olefination and amination [17]. Vanillin can be converted to acetyl dihydroferulic acid, which can itself be polymerized to poly(dihydroferulic acid), having similar thermal properties to PET [18]. Meylemans et al. hydrogenated vanillin to prepare 2-methoxy-4-methylphenol, which was condensed with an aldehyde under acid catalysis to give a substitute of bisphenol A, with potential utility in epoxy resins and polyurethanes [19]. Bai et al. used vanillin and triphosgene to prepare a dialdehyde monomer having a carbonate structure, which can be reduced to the corresponding diol, offering great opportunities to prepare novel polyesters and polyurethanes incorporating a carbonate moiety in the main chain [20]. Zhu et al. prepared a bisphenol structure via a one-pot method using vanillin, diamine and diethyl phosphite, which was then reacted with epichlorohydrin to synthesize a novel bio-based epoxy resin with excellent flame retardancy, as well as good thermal and mechanical properties [21]. Based on this idea, Zhu et al. prepared a vanillin derived mono-epoxide, which could react with a diamine to form a recyclable and high performance thermosetting resin containing a Schiff base structure, and then studied its application in carbon fiber composites [22]. Llevot et al. prepared both a biphenyl bisphenol monomer and a biphenyl esterified monomer using vanillin, and synthesized a series of amorphous thermoplastic polyesters with thermal stability up to $350{ }^{\circ} \mathrm{C}$ by transesterification, showcasing the possibilities of new symmetrical bio-based monomers [23]. Firdaus et al. used a vanillin derived monomer to prepare a series of polymers with molecular weights up to 50 KDa by thiol-ene addition, polycondensation and ADMET polymerization [24]. Wang et al. obtained a resin with a $\mathrm{T}_{\mathrm{g}}$ of up to $184^{\circ} \mathrm{C}$ and a Young's modulus and hardness higher than those of conventional bisphenol A epoxy resins [25]. Tao et al. introduced a trifluorovinyl ether group in vanillin and polymerized the methoxy group in vanillin with disiloxane by the Piers-Rubinsztajn reaction, obtaining a novel fluoro-containing polysiloxane thermoset material [26]. In most cases, a short aliphatic chain was introduced into the polymer backbone in order to provide flexibility between more rigid aromatic sections, thus improving the processability of the polymer [27-29]. For example, Mialon et al. prepared monomers through the reaction of vanillic acid with chloroalkyl alcohols, which provided a tunable aliphatic 'spacer' between aromatic units in the resulting polymers with higher thermal stability and satisfactory $\mathrm{T}_{\mathrm{g}}$ and $\mathrm{T}_{\mathrm{m}}$ comparable to those of PET [30]. The shortcoming of this study lies with the use of high cost and relatively environmentally unfriendly chloroalkyl alcohols. Chen et al. obtained a series of new bio-based polyesters by the polycondensation of novel monomers with hydroxyl and carboxyl groups prepared by aldol condensation of aromatic aldehydes with levulinic acid [31]. Although significant achievements have obtained during the past five years, some of studies still suffered drawbacks of using complex, multiple synthetic steps and non-sustainable feedstocks to prepare polymeric monomers. Therefore, there are still great interests in new approaches to prepare vanillin-based aromatic monomers and their polymers.

Diols are important for polymer synthesis, and vanillin can be readily converted to vanillyl alcohol, a diol, by the reduction of the aldehyde with sodium borohydride. The phenolic alcohol can also, if desired, be functionalized to introduce an aliphatic alcohol. Reza et al. functionalized this phenolic position on vanillin by reacting it with 2-chloroethanol with catalytic potassium carbonate at reflux in DMSO for $6 \mathrm{~h}$ obtained 75\% yield of 4-(2-hydroxyethoxy)-3- methoxybenzaldehyde [32]. Yang et al. performed a similar reaction in dimethylformamide (DMF) at $100{ }^{\circ} \mathrm{C}$ for $5 \mathrm{~h}$ to obtain a yield only of 57\% [33]. Yosuke et al. used acetonitrile as solvent at reflux for $48 \mathrm{~h}$ to obtain a yield only of $42 \%$ [34]. Each of these solvents has problematic aspects from a green chemistry perspective, with DMSO being relatively low-toxicity but having issues with the generation of $\mathrm{SO}_{\mathrm{x}}$ when incinerated, and 
both acetonitrile and especially DMF have problematic toxicity issues. Ethylene carbonate, by contrast, is regarded as a non-toxic and "green" solvent or reagent produced by the cyclic addition reaction of carbon dioxide with ethylene oxide [35-37]. Ethylene oxide can itself can also be attained from renewable resources [38].

Herein, vanillin was firstly converted into 4-(2-hydroxyethoxy)-3-methoxybenzaldehyde using ethylene carbonate as a hydroxyethylation reagent under solvent-free conditions catalyzed by cheap ionic liquids, and then the hydroxyethylated vanillin was reduced to 2-(4-(hydroxymethyl)2-methoxyphenoxy) ethanol using green reducing agent sodium borohydride, giving a useful monomer for the synthesis of series of new polyesters (PE) and polyurethanes (PU). For comparison, the direct reduction of vanillin to produce 4-(hydroxymethyl)-2-methoxyphenol and hence its polymers is also discussed. The structure and thermal properties of as-prepared polyesters and polyurethanes were confirmed and evaluated by various characteristics.

\section{Materials and Methods}

\subsection{Materials}

Vanillin, ethylene carbonate (EC), tetrabutylammonium iodide (TBAI), oxalyl chloride (OC), succinyl chloride (SC), terephthaloyl chloride (TC), vanillyl alcohol (VA), 2.5- furandicarboxylic acid, thionylchloride, dimethylformamide (DMF), pyridine, hexamethylenediisocyanate (HDI), isophoronediisocyanate (IPDI), diphenylmethanediisocyanate (MDI) and 1,8-diazabicyclo [5.4.0]undec7-ene (DBU) were purchased from Aladdin. Sodium borohydride $\left(\mathrm{NaBH}_{4}\right)$ was purchased from Kemel. Tetrahydrofuran (THF) and pyridine were distilled from over calcium hydride before use. Other chemicals were used as received.

\subsection{Procedure for the Synthesis of $H M B D$}

Vanillin $(6.147 \mathrm{~g}, 40 \mathrm{mmol})$ was dissolved in ethylene carbonate $(7.116 \mathrm{~g}, 80 \mathrm{mmol})$ at $80{ }^{\circ} \mathrm{C}$ in a $100 \mathrm{~mL}$ two-neck round bottom flask. Tetrabutylammonium iodide $(2.985 \mathrm{~g}, 8 \mathrm{mmol})$ was added and the reaction heated at $110{ }^{\circ} \mathrm{C}$ for $12 \mathrm{~h}$. When the reaction was cooled to room temperature, deionized water $(20 \mathrm{~mL})$ was added into the mixture and then the mixture was extracted with ethyl acetate $(3 \times 50 \mathrm{~mL})$. The combined organic layers were dried over anhydrous $\mathrm{Na}_{2} \mathrm{SO}_{4}$ and concentrated in vacuo. The crude product was purified by silica gel column chromatography (eluting with ethyl acetate/petroleum ether = 1:1) to afford 4-(2-hydroxyethoxy)-3-methoxybenzaldehyde (HMBD) with yield of $95 \%$.

\subsection{Procedure for the Synthesis s of HMEO}

Sodium borohydride $(1.25 \mathrm{~g}, 9 \mathrm{mmol})$ was added portion wise to a solution of HMBD (1.961 $\mathrm{g}$, $10 \mathrm{mmol}$ ) in $20 \mathrm{~mL}$ of methanol and the resulting mixture was stirred at room temperature for $1 \mathrm{~h}$. The crude product was purified by silica gel column chromatograph (eluting with ethyl acetate/petroleum ether $=1: 1$ ) to afford 2-(4-(hydroxymethyl)-2-methoxyphenoxy) ethan-1-ol (HMEO) with a yield of $81 \%$.

\subsection{Procedure to Prepare PEs}

The diacyl chloride $(2.0 \mathrm{mmol})$ was dropwise added to a stirred solution of HMEO (0.396 g, $2.0 \mathrm{mmol})$ and anhydrous pyridine $(0.354 \mathrm{~mL}, 4.4 \mathrm{mmol})$ in anhydrous THF $(10 \mathrm{~mL})$ under nitrogen at $0{ }^{\circ} \mathrm{C}$. The reaction was allowed to warm to room temperature and stirred for $24 \mathrm{~h}$, after which the reaction mixture was precipitated in methanol. The solid polymer was isolated by filtration, and washed three times with cold methanol, and dried at $40^{\circ} \mathrm{C}$ under vacuum for $24 \mathrm{~h}$ (Scheme 1). 


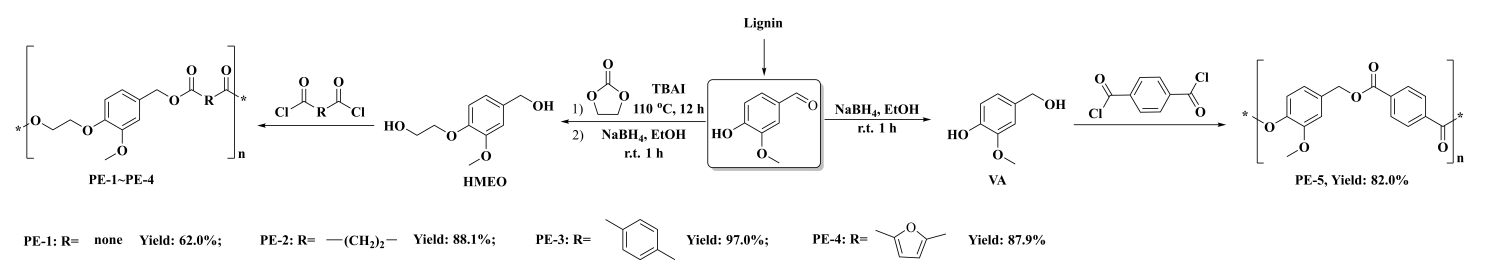

Scheme 1. A green and sustainable pathway to prepare bio-based polyesters from vanillin and ethylene carbonate.

\subsection{Procedure to Prepare PUs}

To a solution of HMEO $(0.396 \mathrm{~g}, 2.0 \mathrm{mmol})$ in anhydrous THF $(10 \mathrm{~mL})$ was added diisocyanate ( $2.0 \mathrm{mmol})$ and DBU $\left(3 \mathrm{~mol} \%\right.$, based on HMEO), the mixture was stirred at $30^{\circ} \mathrm{C}$ for $24 \mathrm{~h}$, after which the reaction the mixture was precipitated into methanol. The polymers were obtained after three times washing with methanol and drying at $40{ }^{\circ} \mathrm{C}$ under vacuum for $24 \mathrm{~h}$ (Scheme 2).

(A)

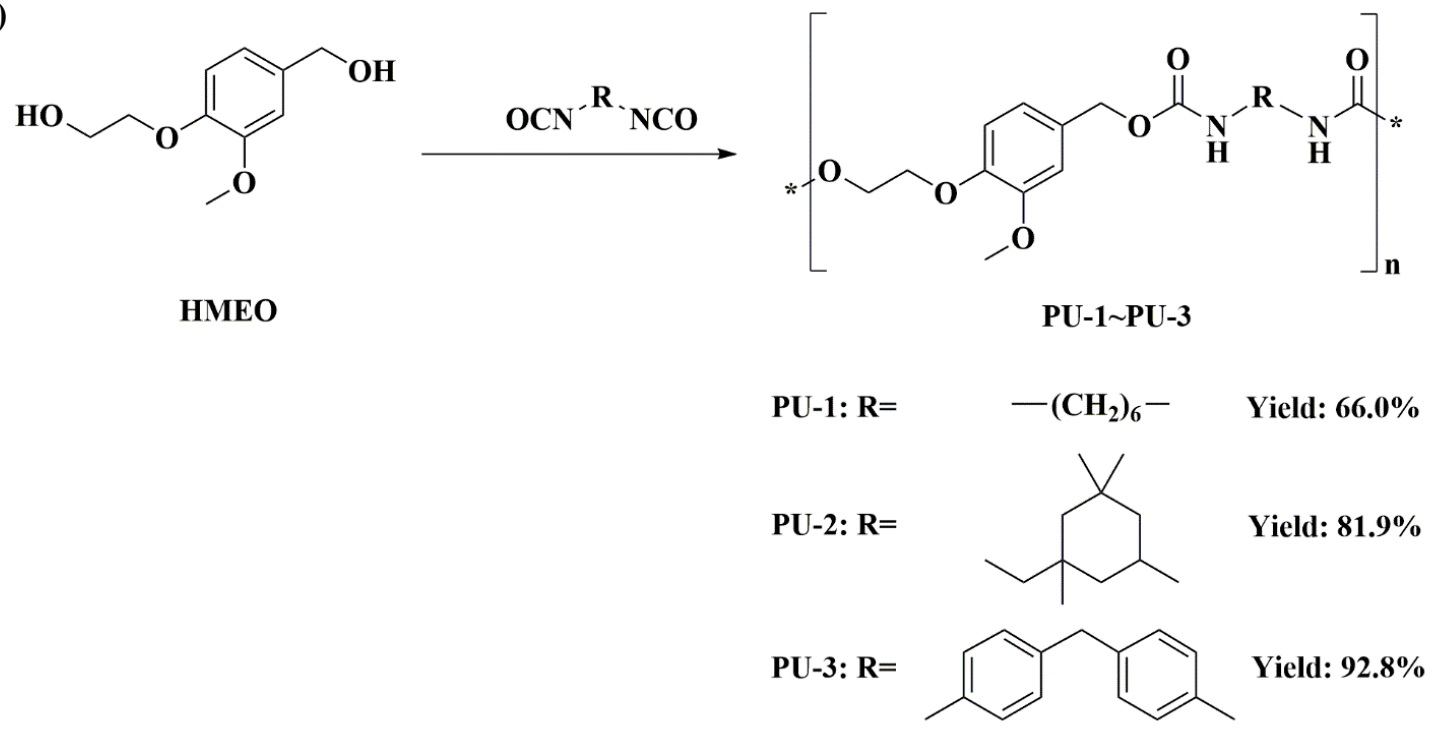

(B)<smiles>COc1cc(CO)ccc1O</smiles>

VA

PU-4, Yield: $81.3 \%$

Scheme 2. (A): The reaction of HMEO with diisocyanatos to prepare PUs; (B): the reaction of vanillyl alcohol (VA) with diphenylmethanediisocyanate to prepare polyurethane.

\subsection{Molecular, Thermal and Structural Characterization}

NMR spectra were recorded on a JOEL ECX500 spectrometer referenced to tetramethylsilane (400 MHz for ${ }^{1} \mathrm{H}$ NMR and $101 \mathrm{MHz}$ for ${ }^{13} \mathrm{C}$ NMR). Fourier-transform infrared (FTIR) spectra were collected on a Thermoscientific Nicolet iS50 instrument at room temperature in the range of $500-4000 \mathrm{~cm}^{-1}$. Polymer molecular weight was measured by gel permeation chromatography (GPC) with DMF with $0.01 \mathrm{M} \mathrm{LiBr}$ as the eluent, at $40{ }^{\circ} \mathrm{C}$ against polystyrene (PS) calibration standards. GPC was performed on a Shimadzu Prominence-i LC-2030C 3D equipped with both a refractive index (RI) and a photo-diode array (PDA) detector, using a Shodex PGC KD-804 column. Thermogravimetric analyses (TGA) were performed on a TA Instruments Q500 instrument at a heating rate of $10^{\circ} \mathrm{C} / \mathrm{min}$ 
under nitrogen atmosphere. Differential scanning calorimetry (DSC) analyses were performed on a TA Instruments Q2000 using hermetically-sealed T-zero aluminum pans. The glass transition temperature $\left(\mathrm{T}_{\mathrm{g}}\right)$ and melting point were taken from the second heating cycle at a rate of $10^{\circ} \mathrm{C} / \mathrm{min}$ under nitrogen atmosphere.

\section{Results and Discussion}

\subsection{Structural Analysis of Monomers}

It was found that the vanillin reacted with ethylene carbonate with no additional solvent, catalyzed by cheap and recyclable tetrabutyl ammonium iodide, producing hydroxyethylated vanillin (HMBD) in $95 \%$ yield. Subsequently, the formyl group in HMBD was reduced with sodium borohydride giving vanillin-based diol monomer (HMEO) in 81\% yield. The formation of HMBD and HMEO were confirmed by ${ }^{1} \mathrm{H}$ NMR and ${ }^{13} \mathrm{C}$ NMR. In the ${ }^{1} \mathrm{H}$ NMR spectrum of HMBD the chemical shift at 4.09 and $3.75 \mathrm{ppm}$ are assigned to the newly formed methylene groups from ethylene carbonate (Figure S1). Meanwhile in the ${ }^{13} \mathrm{C}$ NMR spectrum the chemical shift of newly formed methylene appeared at 70.4 and $59.2 \mathrm{ppm}$ (Figure S2). After reduction, the formyl group transformed to hydroxyl group which was demonstrated by the disappearance of the peak at $9.83 \mathrm{ppm}$ and the appearance of 5.08 and $4.42 \mathrm{ppm}$ in the ${ }^{1} \mathrm{H}$ NMR spectrum of HMEO (Figure S3). In addition, in the ${ }^{13} \mathrm{C}$ NMR spectrum (Figure S4), the complete disappearance of $191.4 \mathrm{ppm}$ and the formation of $62.9 \mathrm{ppm}$ indicated the successful reduction. The obtained HMBD and HMEO were also characterized by FTIR (Figure 1). Compared with vanillin the HMBD shown new peak at $2931 \mathrm{~cm}^{-1}$ which can be attributed to the stretching vibration of newly formed methylene. After reduction, the sharp peak at around $1690 \mathrm{~cm}^{-1}$ assigned to stretching vibration of the carbonyl vanished completely. Meanwhile the strong peak at around $3374 \mathrm{~cm}^{-1}$ can be assigned to the stretching vibration of the hydroxyl in HMEO. The results of NMR and FTIR illustrated the successful synthesis of vanillin-based diol monomer.

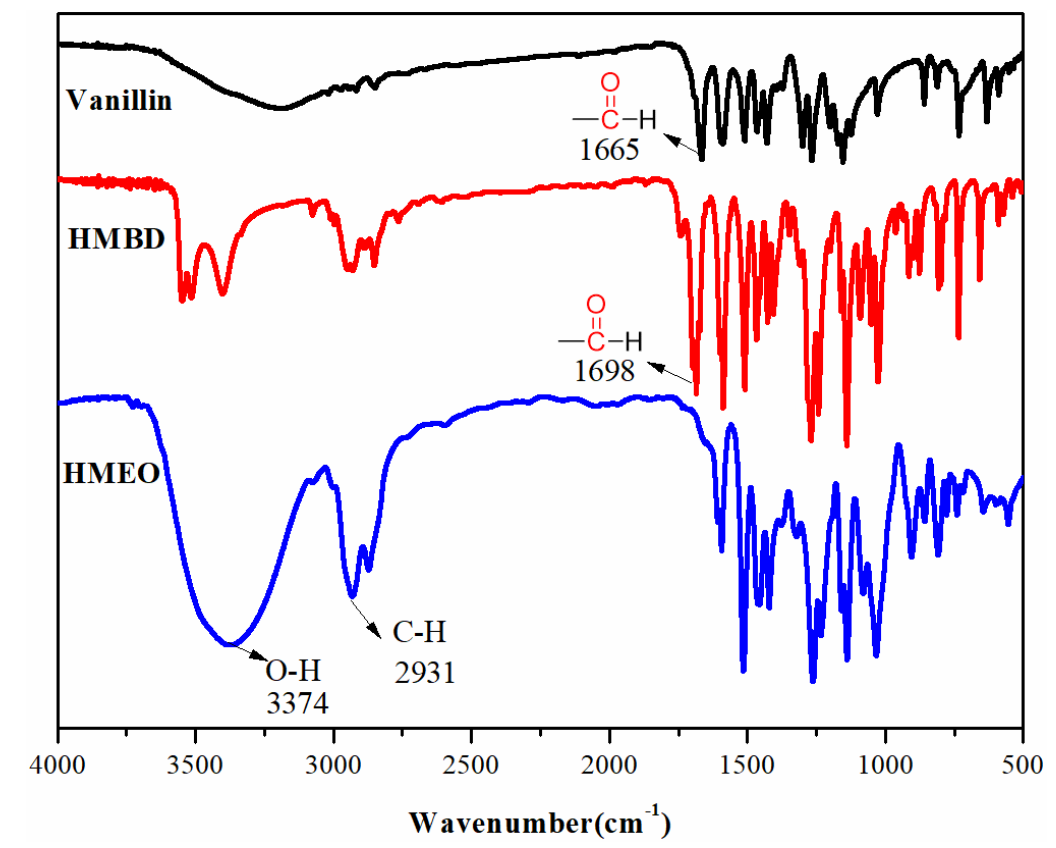

Figure 1. FTIR spectra of vanillin 4-(2-hydroxyethoxy)-3-methoxybenzaldehyde (HMBD) and 2-(4(hydroxymethyl)-2-methoxyphenoxy) ethan-1-ol (HMEO).

\subsection{Structural Analysis of PEs}

With the vanillin-based diol monomer in hand, we prepared polyesters and polyurethanes with diacyl chlorides and diisocyanatos, respectively according to the literature methods [20,39]. A series of polyesters were obtained via direct acylation between HMEO and acyl chlorides including oxalyl 
chloride (OC), succinyl chloride (SC) [40], terephthaloyl chloride (TC) [41] and 2,5-furandicarbonyl dichloride (FC) [42,43]. The 2,5-furandicarboxylic acid has been extensively studied in bio-based polymers [44-46]. For example, Mou et al. prepared a series of furan-based polyester prepared using furyl diol, and found that these polyesters had good thermal properties [47]. Genovese et al. prepared a furan-based polyester through a solvent-free process, starting directly from 2,5-furandicarboxylic acid, the polyester was shown to have excellent oxygen barrier performance superior to PEF [48]. Therefore, we decided to introduce the furan ring into the vanillin-based polyester, in the hope of obtaining bio-based polyesters benefiting from similarly enhanced properties. The 2,5-furandicarbonyl dichloride was prepared according to the literature method [49], and used immediately in the polymerization reaction.

The polymerization was carried out in THF at room temperature for $24 \mathrm{~h}$ using pyridine as a catalyst. After precipitation, all of the polyesters were obtained in high yields (82-97\%) except PE-1 (62\%). Of the polyesters derived from TC, PE-3 show higher yield than PE-5, which may be attributed to the lower reactivity of the phenolic hydroxyl as compared to the aliphatic alcohol.

The structures of obtained polyesters were characterized by NMR and FTIR. Taking PE-2 as a represented example, the chemical shift of hydroxyl at 5.08 and 4.84 ppm disappeared completely while the chemical shift belonging to newly formed methylene appeared at $2.67 \mathrm{ppm}$ in the ${ }^{1} \mathrm{H} N M R$ spectrum (Figure 2A). This result was affirmed by the ${ }^{13} \mathrm{C}$ NMR spectrum (Figure 2B), in which the newly formed methylene appeared at $29.0 \mathrm{ppm}$ while the $-\mathrm{C}=\mathrm{O}$ appeared at $172.4 \mathrm{ppm}$. In the FTIR the newly formed strong peak at around $1740 \mathrm{~cm}^{-1}$ is due to the stretching vibration of $-\mathrm{C}=\mathrm{O}$. (Figure 3 ).

\subsection{Molecular, Thermal and XRD Analysis of PEs}

The GPC and NMR results demonstrated the formation of polyesters with high molecular weight. The $\mathrm{M}_{\mathrm{n}}$ of obtained polyesters were in the range of 17 to $36 \mathrm{KDa}$ with PDI ranging from 1.05-1.14. The $\mathrm{M}_{\mathrm{n}}$ increased as the hindrance of acyl chloride decreased and the use of SC resulted in the highest $\mathrm{M}_{\mathrm{n}}$ of $36 \mathrm{KDa}$ (Table 1).

Table 1. Characterization of polyesters prepared from $\mathrm{HMBO}$ and vanillyl alcohol (VA) with a range of acyl chlorides.

\begin{tabular}{ccccccccc}
\hline Sample & Monomer & $\begin{array}{c}\text { Acyl } \\
\text { Chloride }\end{array}$ & $\begin{array}{c}\text { Yield } \\
\mathbf{( \% )}\end{array}$ & $\begin{array}{c}\mathbf{M}_{\mathbf{n}} \\
\left(\mathbf{g} \mathbf{~ m o l}^{-\mathbf{1}} \mathbf{)}\right.\end{array}$ & $\begin{array}{c}\mathbf{P D I} \\
\left(\mathbf{M}_{\mathbf{w}} / \mathbf{M}_{\mathbf{n}}\right)\end{array}$ & $\begin{array}{c}\mathbf{T}_{\mathbf{g}} \mathbf{( D S C )} \\
\left.\mathbf{(}{ }^{\circ} \mathbf{C}\right)\end{array}$ & $\begin{array}{c}\mathbf{T}_{\mathbf{d}} \mathbf{( 5 \% )} \\
\left.\mathbf{(}{ }^{\circ} \mathbf{C}\right)\end{array}$ & $\begin{array}{c}\mathbf{T}_{\mathbf{d}} \mathbf{( 5 0 \% )} \\
\left.\mathbf{(}{ }^{\circ} \mathbf{C}\right)\end{array}$ \\
\hline PE-1 & HMEO & OC & 62.0 & 22,000 & 1.06 & 73.4 & 153 & 393 \\
PE-2 & HMEO & SC & 88.1 & 36,000 & 1.14 & 16.2 & 214 & 392 \\
PE-3 & HMEO & TC & 97.0 & 17,000 & 1.05 & 58.4 & 257 & 408 \\
PE-4 & HMEO & FC & 87.9 & 19,000 & 1.10 & 57.5 & 264 & 407 \\
PE-5 & VA & TC & 82.0 & 21,000 & 1.11 & 81.2 & 293 & 460 \\
\hline
\end{tabular}

The thermal properties of the PEs were examined by TGA (Figure 4A, Table 1) and DSC (Figure 4B, Table 1). PE-2, PE-3 and PE-4 showed higher thermal stability with $5 \%$ mass loss occurring at 214, 257 and $264^{\circ} \mathrm{C}$, respectively, and the thermal properties of PE-3 and PE-4 are very similar. While PE-1 exhibited lower thermal stability with $5 \%$ mass loss occurred at $153{ }^{\circ} \mathrm{C}$. Compared with PE-5, due to the presence of short fatty segments in PE-3, the thermal stability with $5 \%$ mass loss occurring at $257^{\circ} \mathrm{C}$, PE-5 showed higher thermal stability with $5 \%$ mass loss increased to $293^{\circ} \mathrm{C}$. All polyesters underwent at least two stages of decomposition, likely due to the breakdown of ester bonds and benzene rings. The residual weight at $700{ }^{\circ} \mathrm{C}$ decreased as follow: PE- $5>$ PE- $4>$ PE- $3>$ PE- $2>$ PE- 1 , implying that residual weight is related to the rigid aromatic group content for the polyester. The $\mathrm{T}_{\mathrm{g}}$ increased from 16.2 to $73.4^{\circ} \mathrm{C}$ as the carbon number of acyl chloride decreased from 4 to 2 , which may due to the decreased flexibility of the aliphatic chain (Table 1, PE1 and 2). While using TC or FC, polyesters with high $\mathrm{T}_{\mathrm{g}}$ were obtained (Table 1, PE3 and 4), the $\mathrm{T}_{\mathrm{g}}$ of PE-4 is similar to PE-3 indicating that the furan-based polyester has similar properties to the benzene-based polyester, and their $T_{g} \mathrm{~s}$ are much 
higher than that of PBT $\left(38^{\circ} \mathrm{C}\right)$. Compared with PE-3, PE-5 showed increased $\mathrm{T}_{\mathrm{g}}$ as the rigidity of the diol increased and both their $\mathrm{T}_{\mathrm{g}}$ s are comparable or even higher than those of PBT and PET (38 and $67^{\circ} \mathrm{C}$, respectively) [31]. Although no melting point was observed for any of these polyesters, the XRD results indicated that the PE-2 is amorphous, whilst the other polyesters contain partial crystalline regions (Figure 5).

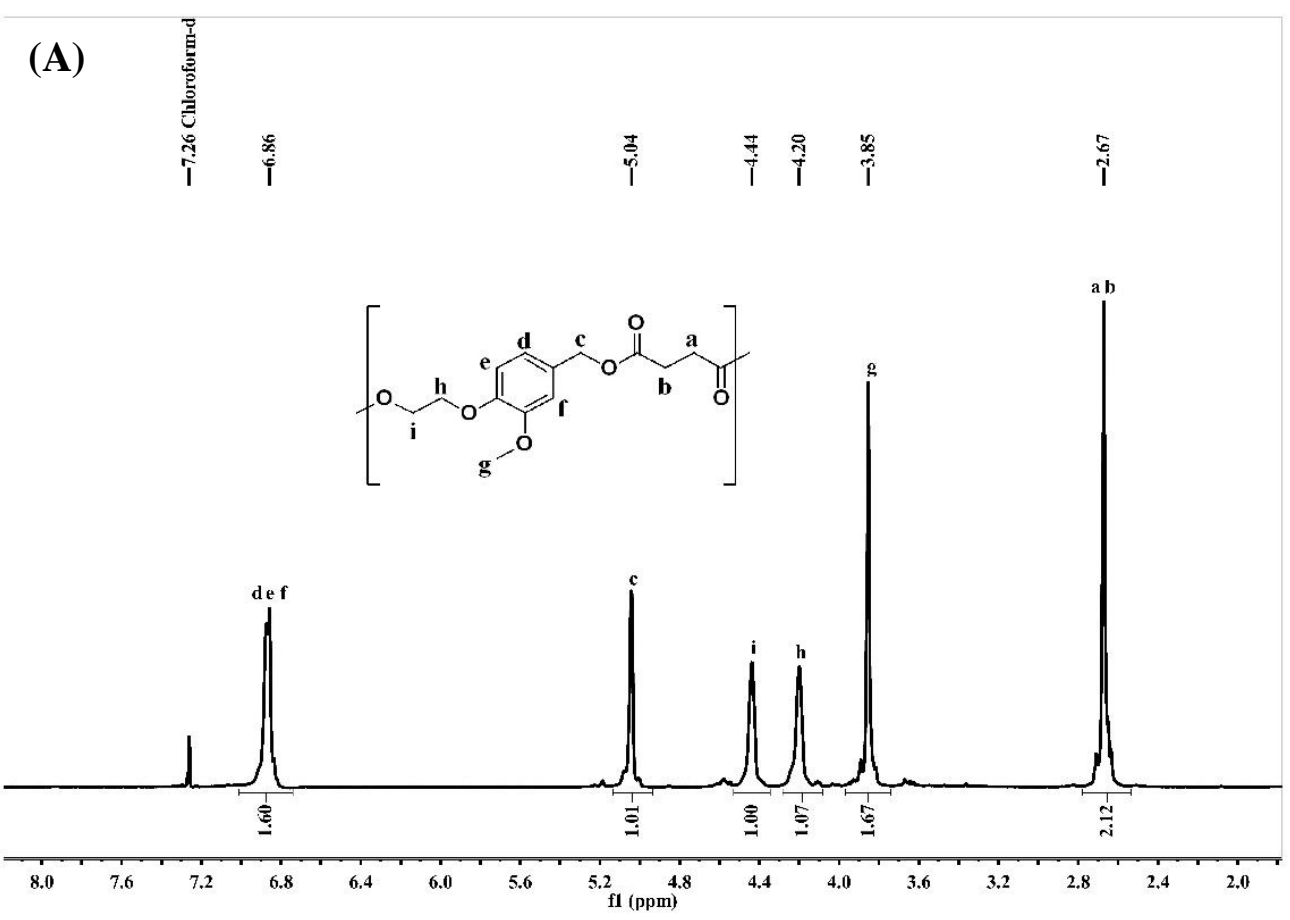

(B)

B)

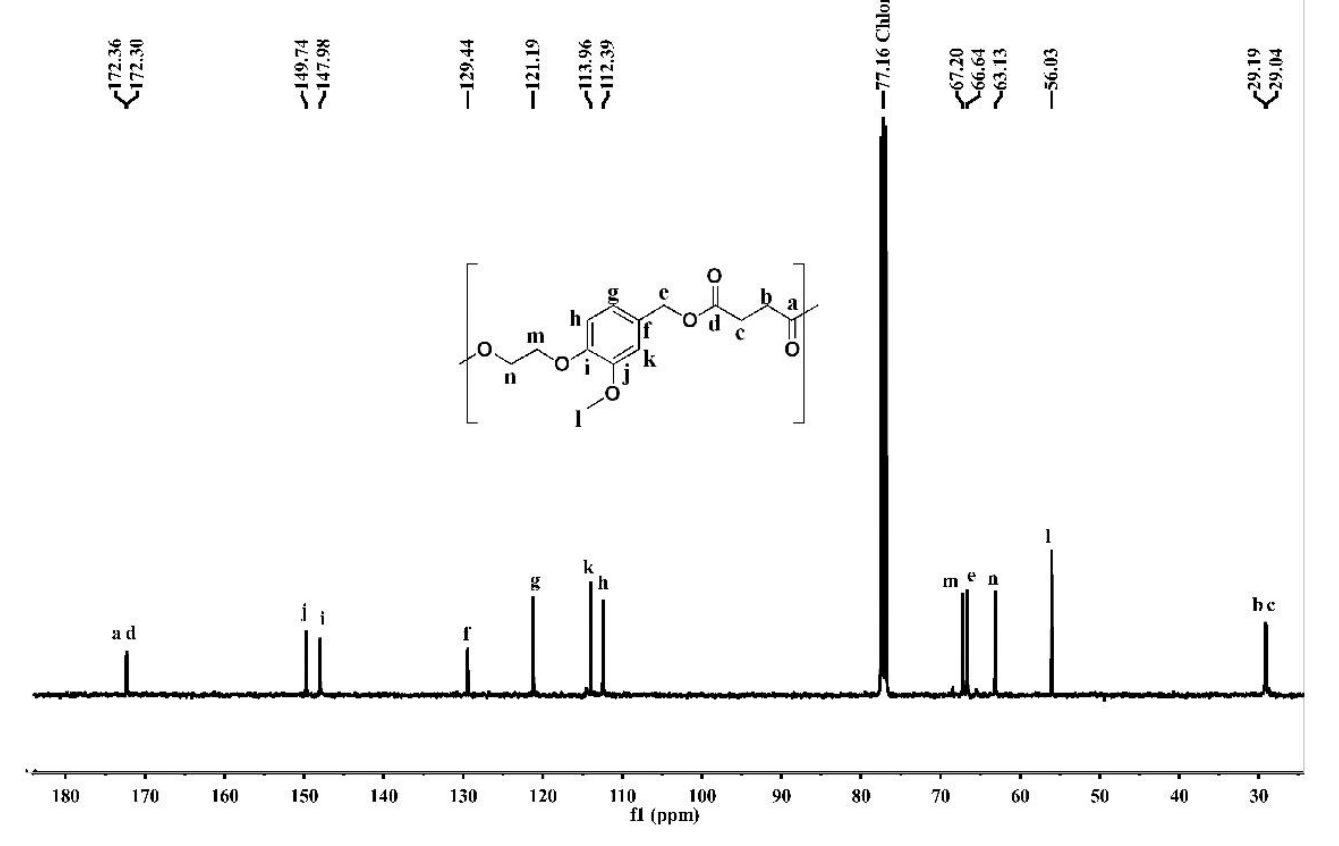

Figure 2. ${ }^{1} \mathrm{H}(\mathbf{A})$ and ${ }^{13} \mathrm{C}$ NMR (B) spectra of PE-2. 


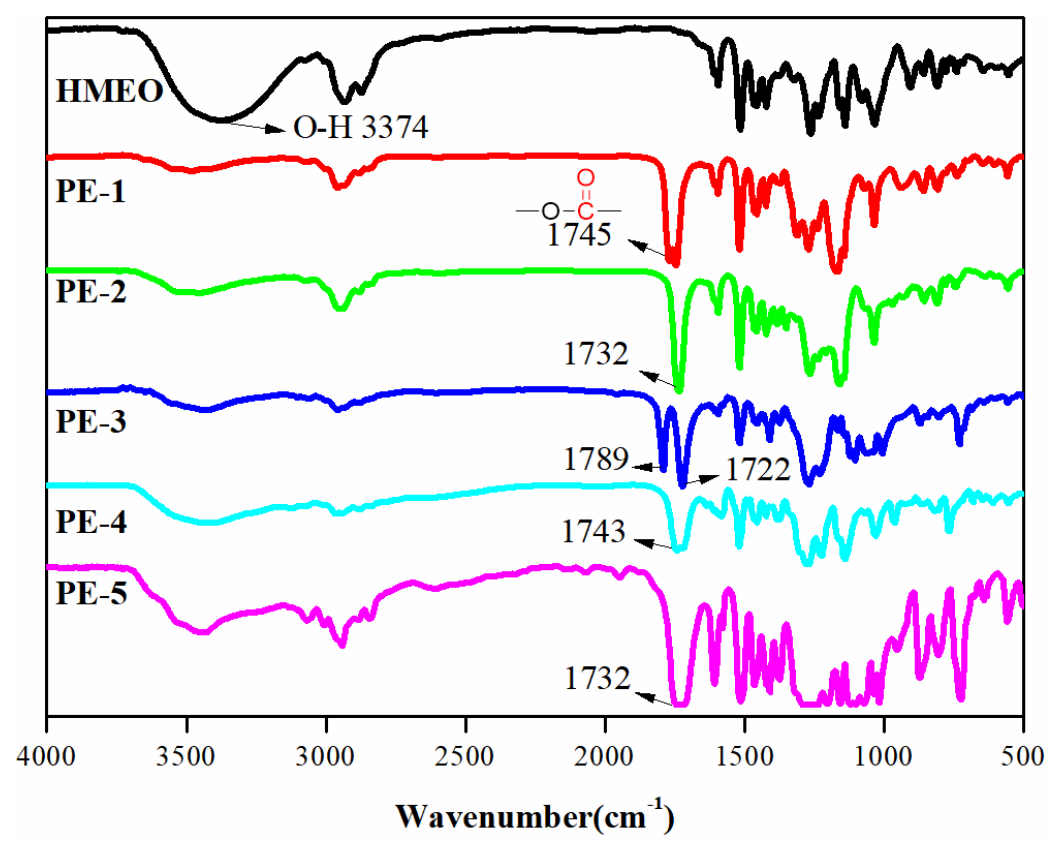

Figure 3. FTIR spectra of PEs and HMEO.
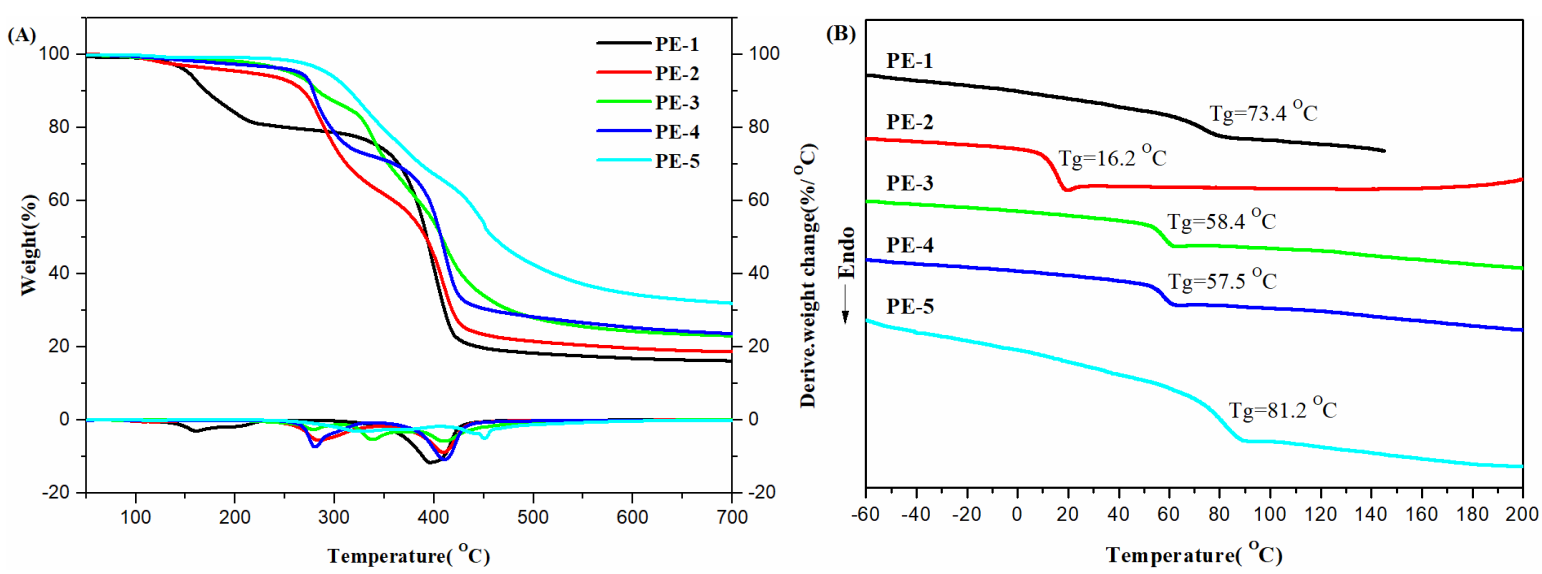

Figure 4. TGA curves (A) and differential scanning calorimetry (DSC) traces (B) of PEs.

\subsection{Structural Analysis of PUs}

Polyurethane has been widely used in various applications including upholstery, building materials, and transportation [50,51]. The traditional method to prepare polyurethanes is via the polyaddition of polyols and polyisocyanates [52]. Due to the high atom economy of this polyaddition, the use of bio-based polyols is particularly interesting to replace the use of less sustainable petroleum based monomers in these applications [53,54]. Therefore, a series of vanillin-based polyurethanes were prepared by polyaddition of HMEO monomer and diisocyanatos catalyzed by DBU in THF, including hexamethylenediisocyanate (HDI), isophoronediisocyanate (IPDI), diphenylmethanediisocyanate (MDI). In contrast, PU-4 was prepared from vanillyl alcohol (VA) and diphenylmethanediisocyanate (MDI). It is worth mentioning that isocyanates do have significant issues with their toxicity and hazardous, vigorous reactivity with moisture, and we acknowledge that much important work is being done (including by these authors) on non-isocyanate polyurethanes (NIPUs) $[55,56]$. However, these technologies, whilst safer, are not yet mature. The development of bio-based polyols offers a more sustainable alternative (compared conventional methods) that might realistically be brought into use 
in a far shorter timescale, indeed soybean-derived polyols have been used commercially in car seat foams for many years [57].

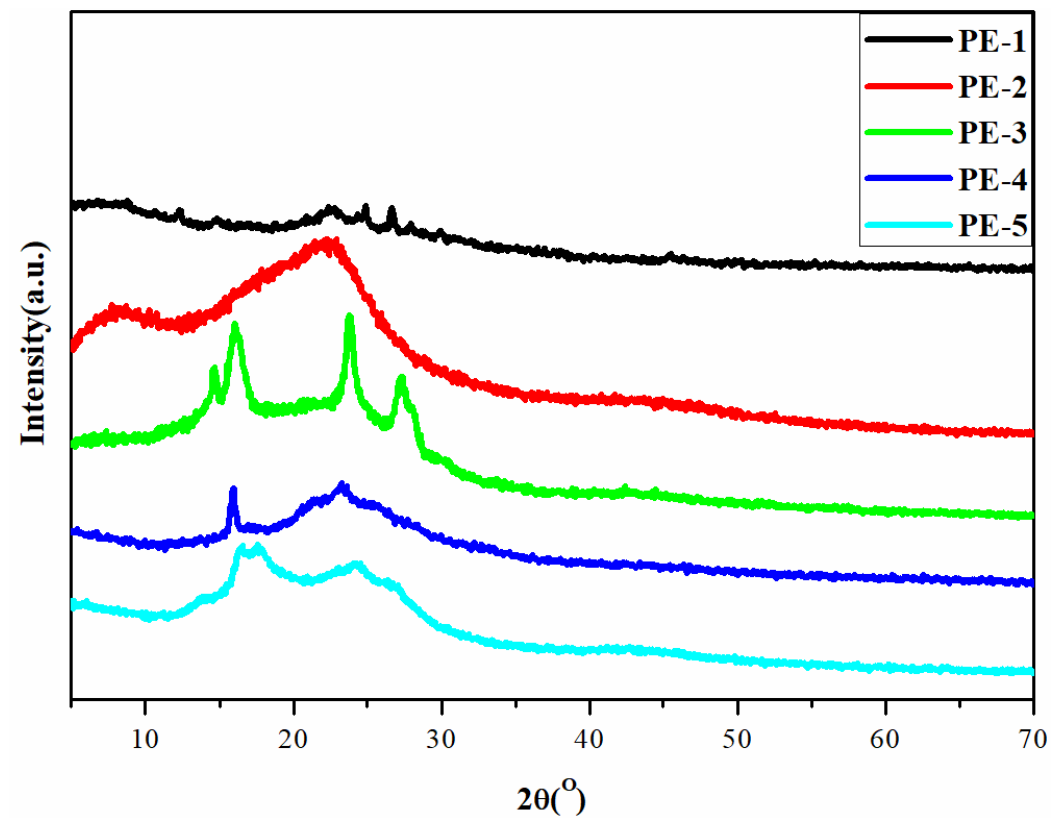

Figure 5. XRD curves of PEs.

The structures of PUs were determined by ${ }^{1} \mathrm{H}$ NMR and ${ }^{13} \mathrm{C}$ NMR (Figures S15-S22). Taking PU-3 as an example, there are no peaks of hydroxyl group at $5.08 \mathrm{ppm}$ and $4.84 \mathrm{ppm}$, while the typical chemical shifts of amide proton appears at $9.64 \mathrm{ppm}$ and $9.74 \mathrm{ppm}$. The multiple peaks at 7.38-7.05 ppm represent the characteristic peaks of benzene ring (Figure $6 \mathrm{~A}$ ). In the ${ }^{13} \mathrm{C}$ NMR spectrum of PU-3 (Figure 6B) the chemical shift at 153.4 ppm can be assigned to the new carbonyl environment of the urethane functionality.

The formation of these PUs were further confirmed by FTIR (Figure 7). In the FTIR spectra of PUs the hydroxyl peak at $3374 \mathrm{~cm}^{-1}$ is replaced by the amino at $3317 \mathrm{~cm}^{-1}$. The new strong signal at 1698 $\mathrm{cm}^{-1}$ further demonstrates the presence of the urethane backbone.

\subsection{Molecular, Thermal and XRD analysis of PUs}

The yields of those PUs obtained from HMEO are above $80 \%$, except PU-1 which give a more modest yield of $66 \%$ (Table 2). PU-4 derived from vanillic alcohol exhibits a lower yield of $81.3 \%$ as compared with PU-3, which may due to the lower activity of phenolic hydroxyl. The GPC results reveal that PUs of high Mn are successfully prepared, with $\mathrm{M}_{\mathrm{n}}$ and PDI in the range of 21-40 KDa and 1.10-1.23, respectively. Compared with PU-3, PU-4 show lower $\mathrm{M}_{n}$, which may be attributed to the lower reactivity of the phenolic hydroxyl as compared to the aliphatic alcohol. The thermal properties of the PUs are examined by TGA (Figure 8A, Table 2) and DSC (Figure 8B, Table 2). TGA reveals that all of these polyurethanes have excellent thermal stability, with an initial decomposition temperature $\left(5 \%\right.$ weight loss) between $229-280^{\circ} \mathrm{C}$. The initial decomposition temperature of PU-2 is higher than that of PU-3, indicating that the thermal stability of this IPDI-based polyurethane is higher than the aromatic-based polyurethane. Due to the presence of flexible aliphatic segments in PU-3\% mass loss occurred at $229^{\circ} \mathrm{C}$, whereas PU-4 with a more rigid vanillic diol derived backbone shows higher thermal stability with $5 \%$ mass loss increases to $280^{\circ} \mathrm{C}$ and no observed $\mathrm{T}_{\mathrm{g}}$. 
(A)

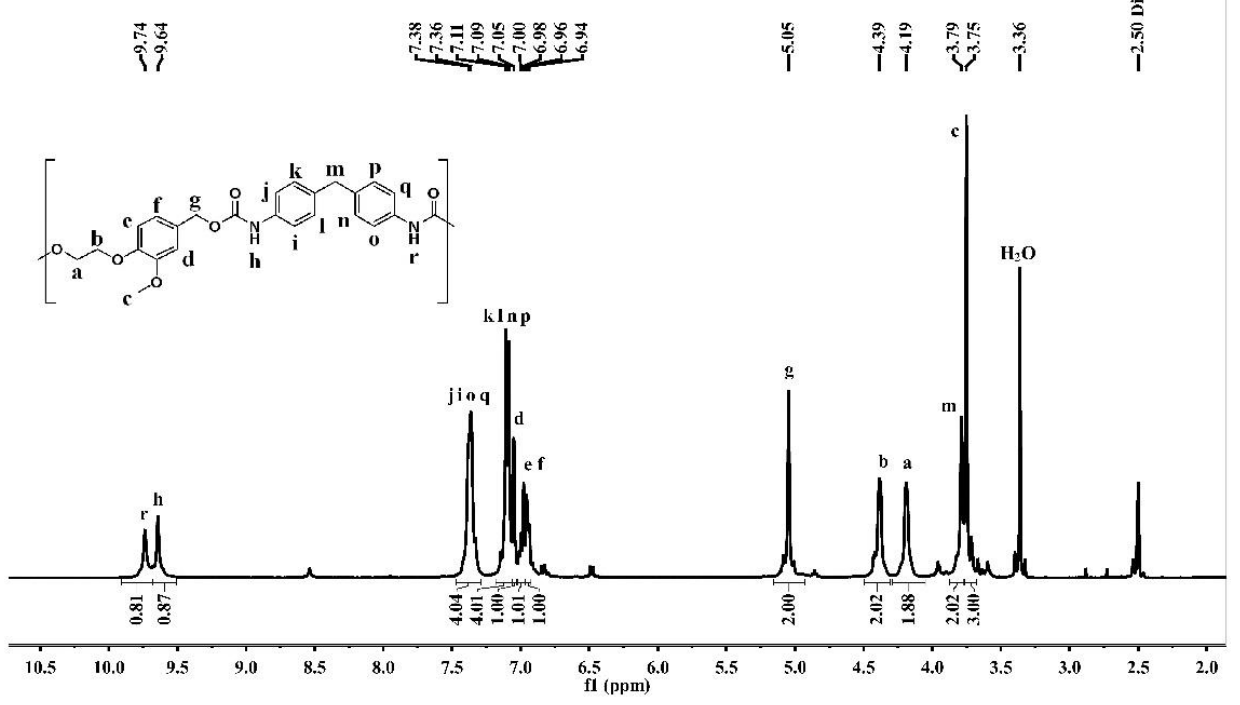

(B)

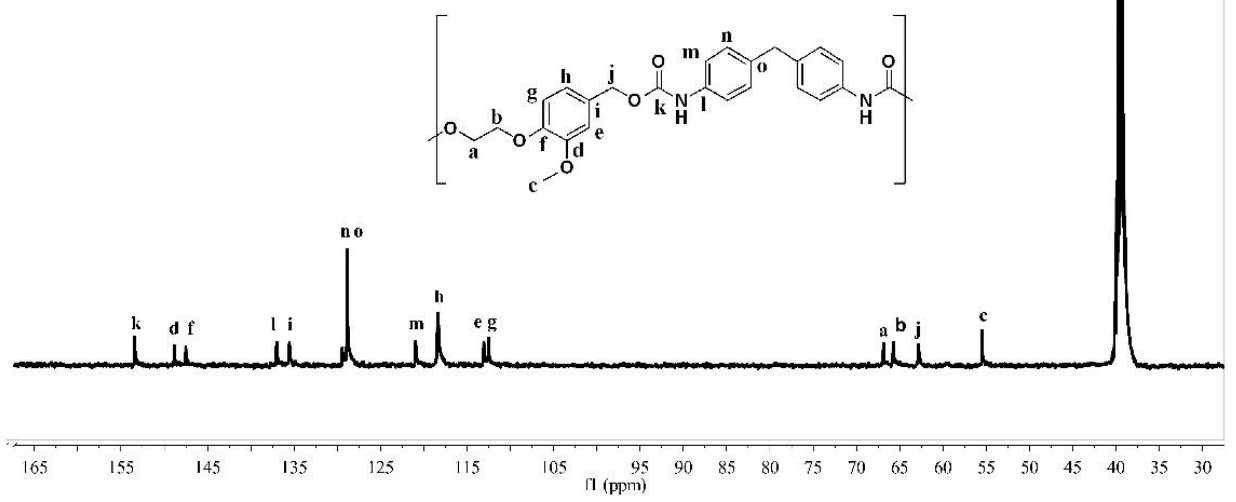

Figure 6. Comparative ${ }^{1} \mathrm{H}$ NMR spectra of PU-3 (A) and ${ }^{13} \mathrm{C}$ NMR spectra of PU-3 (B).

Table 2. Test data based on the PUs.

\begin{tabular}{ccccccccc}
\hline Sample & Monomer & Diisocyanate & $\begin{array}{c}\text { Yield } \\
\mathbf{( \% )}\end{array}$ & $\begin{array}{c}\mathbf{M}_{\mathbf{n}} \\
\left(\mathbf{g ~ m o l}^{-\mathbf{1}}\right)\end{array}$ & $\begin{array}{c}\text { PDI } \\
\left(\mathbf{M}_{\mathbf{w}} / \mathbf{M}_{\mathbf{n}}\right)\end{array}$ & $\begin{array}{c}\mathbf{T}_{\mathrm{g}} \\
(\mathbf{D S C}) \\
\left({ }^{\circ} \mathbf{C}\right)\end{array}$ & $\begin{array}{c}\mathbf{T}_{\mathbf{d}} \\
(\mathbf{5 \%}) \\
\left({ }^{\circ} \mathbf{C}\right)\end{array}$ & $\begin{array}{c}\mathbf{T}_{\mathbf{d}} \\
(\mathbf{5 0} \%) \\
\left({ }^{\circ} \mathbf{C}\right)\end{array}$ \\
\hline PU-1 & HMEO & $\begin{array}{c}\text { Hexamethylenediisocyanate } \\
\text { (HDI) }\end{array}$ & 66.0 & 39,000 & 1.23 & 11.6 & 259 & 351 \\
PU-2 & HMEO & $\begin{array}{c}\text { Isophoronediisocyanate } \\
\text { (IPDI) }\end{array}$ & 81.9 & 29,000 & 1.11 & 66.8 & 252 & 325 \\
PU-3 & HMEO & $\begin{array}{c}\text { Diphenylmethanediisocyanate } \\
\text { (MDI) }\end{array}$ & 92.8 & 40,000 & 1.11 & 80.4 & 229 & 373 \\
PU-4 & VA & MDI & 81.3 & 21,000 & 1.10 & - & 280 & 364 \\
\hline
\end{tabular}




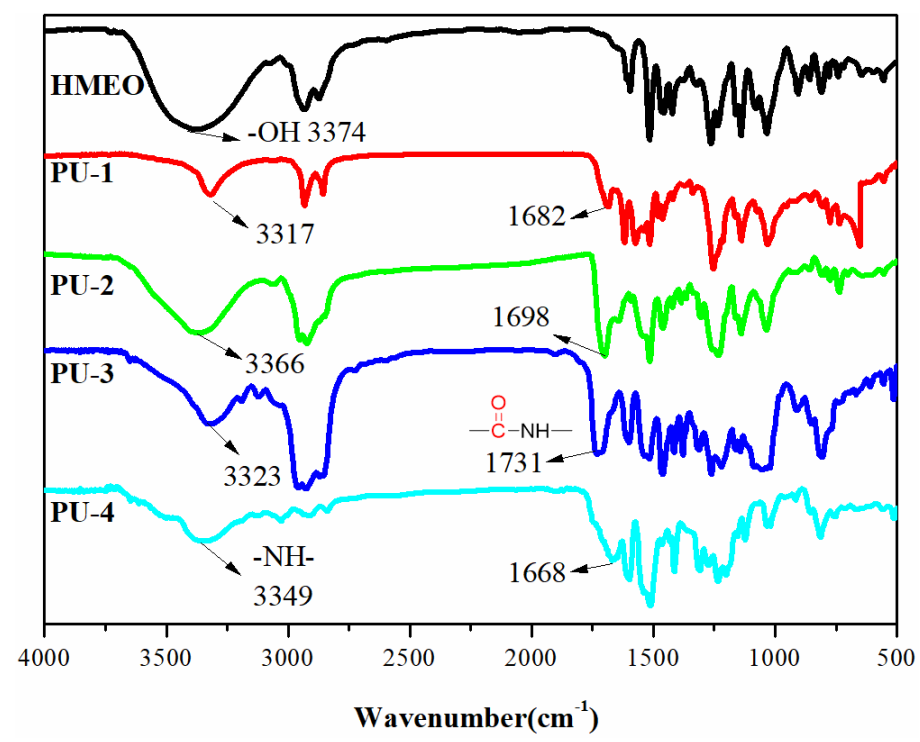

Figure 7. FTIR spectra of PUs and HMEO.
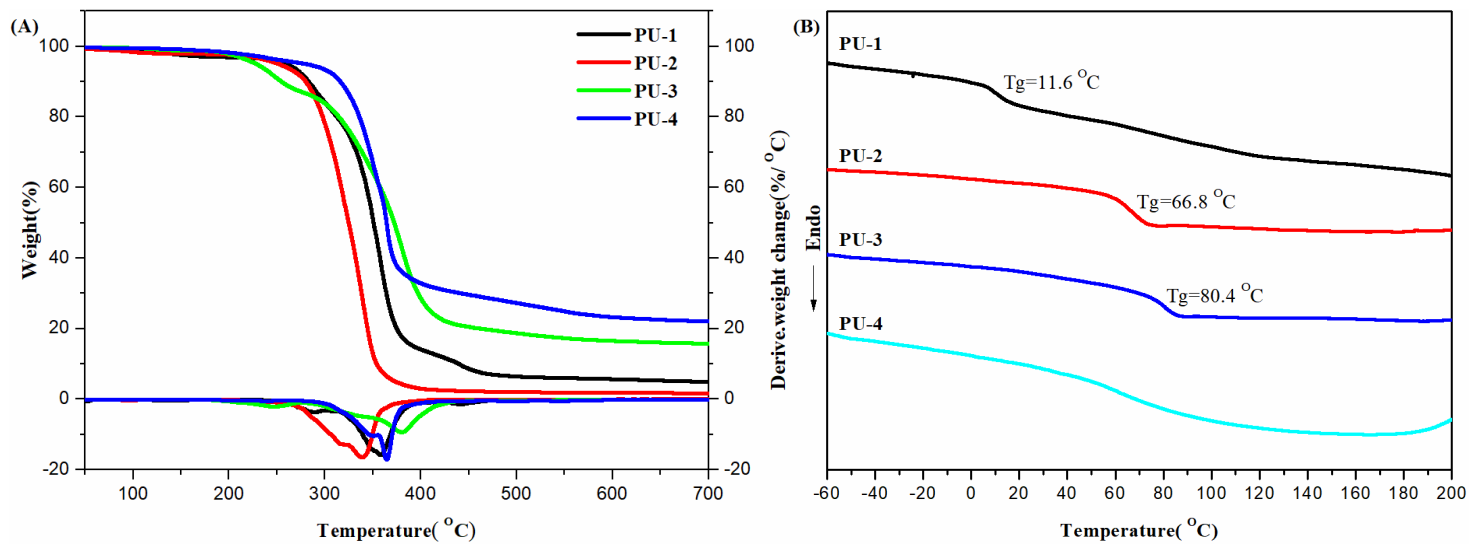

Figure 8. TGA curves (A) and DSC traces (B) of PUs.

The $\mathrm{T}_{\mathrm{g}}$ of PUs increases from 11.6 to $80.4^{\circ} \mathrm{C}$ with increased chain rigidity. The $\mathrm{T}_{\mathrm{g}}$ of IPDI- based PU-2 and MDI-based PU-3 is $66.8{ }^{\circ} \mathrm{C}$ and $80.4{ }^{\circ} \mathrm{C}$, respectively (Table 2, Run 2 and 3) and this is likely because the MDI-based polyurethane backbone has higher rigidity than the aliphatic-isocyanate IPDI-based polyurethane [58]. The initial decomposition temperature of PU-3 is lower than PU-4 due to the presence of two methylene soft segments on the main chain of PU-3. PU-4 shows no $\mathrm{T}_{\mathrm{g}}$ before the initial decomposition temperature. No melting point was detected for any of these PUs, indicating that they were amorphous, which was also consistent with the XRD data (Figure 9). 


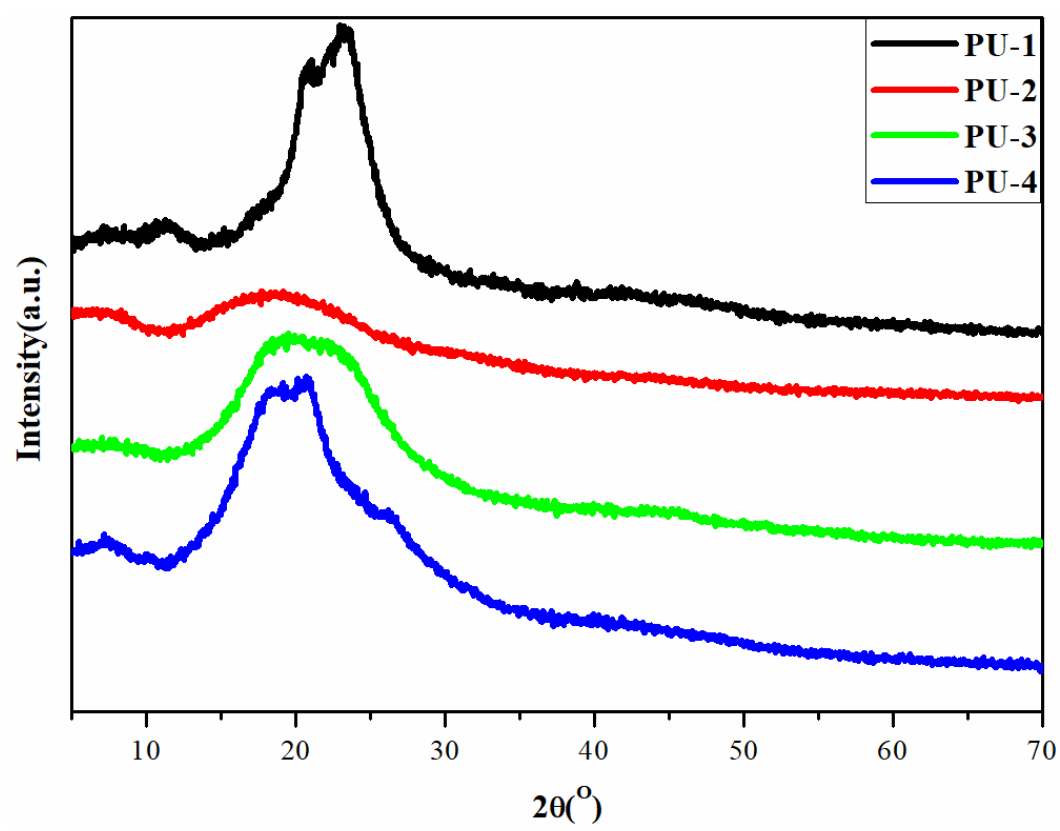

Figure 9. XRD curves of PUs.

\section{Conclusions}

In this paper, HMBD and HMEO have been synthesized in high yields starting from bio-based vanillin and ethylene carbonate via an environmentally sustainable catalytic method. HMEO was employed for the preparation of polyesters and polyurethanes. The results of ${ }^{1} \mathrm{H}$ NMR, ${ }^{13} \mathrm{C}$ NMR, FTIR and GPC confirmed the successful preparation of high $\mathrm{M}_{n}$ polyesters and polyurethanes demonstrating their potential as sustainable polymer materials. The DSC analyses revealed that the $\mathrm{T}_{\mathrm{g}}$ of obtained polymers were closely correlated with the degree of flexibility (or rigidity) present in the polymer chain. Through PE-3 with PE-5 and PU-3 with PU-4 performance comparison showed that the higher reactivity of the aliphatic hydroxyl group and the flexibility of the alkyl segment had a great influence on the yield, molecular weight and thermal properties of polymer, which provided an important reference for the design of new materials. These two families of lignin-derivable polymers have bio-based content between $44 \%$ and $100 \%$, and are therefore of extreme interest as more sustainable future materials.

Supplementary Materials: The following are available online at http://www.mdpi.com/2073-4360/12/3/586/s1, Figure S1. ${ }^{1} \mathrm{H}$ NMR spectrum of HMBD; Figure S2. ${ }^{13} \mathrm{C}$ NMR spectrum of HMBD; Figure S3. ${ }^{1} \mathrm{H}$ NMR spectrum of HMEO; Figure S4. ${ }^{13} \mathrm{C}$ NMR spectrum of HMEO; Figure S5. ${ }^{1} \mathrm{H}$ NMR spectrum of PE-1; Figure S6. ${ }^{13} \mathrm{C}$ NMR spectrum of PE-1; Figure S7. ${ }^{1} \mathrm{H}$ NMR spectrum of PE-2; Figure S8. ${ }^{13} \mathrm{C}$ NMR spectrum of PE-2; Figure S9. ${ }^{1} \mathrm{H}$ NMR spectrum of PE-3; Figure S10. ${ }^{13} \mathrm{C}$ NMR spectrum of PE-3; Figure S11. ${ }^{1} \mathrm{H}$ NMR spectrum of PE-4; Figure S12. ${ }^{13} \mathrm{C}$ NMR spectrum of PE-4; Figure S13. ${ }^{1} \mathrm{H}$ NMR spectrum of PE-5; Figure S14. ${ }^{13} \mathrm{C}$ NMR spectrum of PE-5; Figure S15. ${ }^{1} \mathrm{H}$ NMR spectrum of PU-1; Figure S16. ${ }^{13} \mathrm{C}$ NMR spectrum of PU-1; Figure S17. ${ }^{1} \mathrm{H}$ NMR spectrum of PU-2; Figure S18. ${ }^{13} \mathrm{C}$ NMR spectrum of PU-2; Figure S19. ${ }^{1} \mathrm{H}$ NMR spectrum of PU-3; Figure S20. ${ }^{13} \mathrm{C}$ NMR spectrum of PU-3; Figure S21. ${ }^{1} \mathrm{H}$ NMR spectrum of PU-4; Figure S22. ${ }^{13} \mathrm{C}$ NMR spectrum of PU-4, which provide ${ }^{1} \mathrm{H}$ and ${ }^{13} \mathrm{C}$ NMR spectra of monomers and polymers.

Author Contributions: C.Z. and H.X. conceived and designed the experiments; C.Z. performed the experiments and analyzed the data; X.Z., T.R. and C.H. cooperated with characterization in molecular and thermal properties of materials; C.Z., I.D.V.I., H.X. and Q.C. wrote the paper. All authors have read and agreed to the published version of the manuscript.

Funding: This research was financially supported by the National Natural Science Foundation of China (NSFC 21704019, 21644012); Science and Technology Department of Guizhou Province (Grant No. Platform and Talents [2016]5652; [2019]5607).

Conflicts of Interest: The authors declare no conflict of interest. 


\section{References}

1. Corma, A.; Iborra, S.; Velty, A. Chemical Routes for the Transformation of Biomass into Chemicals. Chem. Rev. 2007, 107, 2411-2502. [CrossRef]

2. Wang, H.; Zhang, Y.; Wang, C. Surface modification and selective flotation of waste plastics for effective recycling-A review. Sep. Purif. Technol. 2019, 226, 75-94. [CrossRef]

3. Vilela, C.; Sousa, A.F.; Fonseca, A.C.; Serra, A.C.; Coelho, J.F.J.; Freire, C.S.R.; Silvestre, A.J.D. The quest for sustainable polyesters-Insights into the future. Polym. Chem. 2014, 5, 3119-3141. [CrossRef]

4. Espro, C.; Gumina, B.; Szumelda, T.; Paone, E.; Mauriello, F. Catalytic Transfer Hydrogenolysis as an Effective Tool for the Reductive Upgrading of Cellulose. Hemicellulose, Lignin, and Their Derived Molecules. Catalysts 2018, 8, 313. [CrossRef]

5. Kosinkova, J.; Doshi, A.; Maire, J.; Ristovski, Z.; Brown, R.; Rainey, T.J. Measuring the regional availability of biomass for biofuels and the potential for microalgae. Renew. Sustain. Energy Rev. 2015, 49, 1271-1285. [CrossRef]

6. $\mathrm{Xu}, \mathrm{X} .-\mathrm{L} . ;$ Chen, H.H. Examining the efficiency of biomass energy: Evidence from the Chinese recycling industry. Energy Policy 2018, 119, 77-86. [CrossRef]

7. Kumar, P.; Barrett, D.M.; Delwiche, M.J.; Stroeve, P. Methods for Pretreatment of Lignocellulosic Biomass for Efficient Hydrolysis and Biofuel Production. Ind. Eng. Chem. Res 2009, 48, 3713-3729. [CrossRef]

8. Zhu, Y.; Romain, C.; Williams, C.K. Sustainable polymers from renewable resources. Nature 2016, 540, 354-362. [CrossRef] [PubMed]

9. Kuznetsov, B.N.; Taraban'ko, V.E.; Kuznetsova, S.A. New catalytic methods for obtaining cellulose and other chemical products from vegetable biomass. Kinet. Catal. 2008, 49, 517-526. [CrossRef]

10. Verdia, P.; Brandt, A.; Hallett, J.P.; Ray, M.J.; Welton, T. Fractionation of lignocellulosic biomass with the ionic liquid 1-butylimidazolium hydrogen sulfate. Green Chem. 2014, 16, 1617-1627. [CrossRef]

11. Dai, C.; Tao, J.; Zhao, M.; Jiang, B. Energetic Efficiency and Environmental. Economic, Societal Benefits of Microdiesel From Biowastes. Energy Explor. Exploit. 2007, 25, 219-226. [CrossRef]

12. Priefert, H.; Rabenhorst, J.A. Steinbüchel, Biotechnological production of vanillin. Appl. Microbiol. Biotechnol. 2001, 56, 296-314. [CrossRef] [PubMed]

13. Gallage, N.J.; Moller, B.L. Vanillin-bioconversion and bioengineering of the most popular plant flavor and its de novo biosynthesis in the vanilla orchid. Mol. Plant 2015, 8, 40-57. [CrossRef] [PubMed]

14. Fache, M.; Boutevin, B.; Caillol, S. Vanillin Production from Lignin and Its Use as a Renewable Chemical. ACS Sustain. Chem. Eng. 2015, 4, 35-46. [CrossRef]

15. Fache, M.; Boutevin, B.; Caillol, S. Vanillin, a key-intermediate of biobased polymers. Eur. Polym. J. 2015, 68, 488-502. [CrossRef]

16. Isikgor, F.H.; Becer, C.R. Lignocellulosic biomass: A sustainable platform for the production of bio-based chemicals and polymers. Polym. Chem. 2015, 6, 4497-4559. [CrossRef]

17. Fache, M.; Darroman, E.; Besse, V.; Auvergne, R.; Caillol, S.; Boutevin, B. Vanillin, a promising biobased building-block for monomer synthesis. Green Chem. 2014, 16, 1987-1998. [CrossRef]

18. Mialon, L.; Pemba, A.G.; Miller, S.A. Biorenewable polyethylene terephthalate mimics derived from lignin and acetic acid. Green Chem. 2010, 12, 1704-1706. [CrossRef]

19. Meylemans, H.A.; Groshens, T.J.; Harvey, B.G. Synthesis of renewable bisphenols from creosol. ChemSusChem 2012, 5, 206-210. [CrossRef]

20. Bai, D.; Chen, Q.; Chai, Y.; Ren, T.; Huang, C.; Ingram, I.D.V.; North, M.; Zheng, Q.; Xie, H. Vanillin derived a carbonate dialdehyde and a carbonate diol: Novel platform monomers for sustainable polymers synthesis. RSC Adv. 2018, 8, 34297-34303. [CrossRef]

21. Wang, S.; Ma, S.; Xu, C.; Liu, Y.; Dai, J.; Wang, Z.; Liu, X.; Chen, J.; Shen, X.; Wei, J.; et al. Vanillin-Derived High-Performance Flame Retardant Epoxy Resins: Facile Synthesis and Properties. Macromolecules 2017, 50, 1892-1901. [CrossRef]

22. Wang, S.; Ma, S.; Li, Q.; Xu, X.; Wang, B.; Yuan, W.; Zhou, S.; You, S.; Zhu, J. Facile in situ preparation of high-performance epoxy vitrimer from renewable resources and its application in nondestructive recyclable carbon fiber composite. Green Chem. 2019, 21, 1484-1497. [CrossRef]

23. Llevot, A.; Grau, E.; Carlotti, S.; Grelier, S.; Cramail, H. Renewable (semi)aromatic polyesters from symmetrical vanillin-based dimers. Polym. Chem. 2015, 6, 6058-6066. [CrossRef] 
24. Firdaus, M.; Meier, M.A.R. Renewable co-polymers derived from vanillin and fatty acid derivatives. Eur. Polym. J. 2013, 49, 156-166. [CrossRef]

25. Yuan, W.C.; Ma, S.Q.; Wang, S.; Li, Q.; Wang, B.B.; Xu, X.W.; Huang, K.F.; Chen, J.; You, S.S.; Zhu, J. Synthesis of fully bio-based diepoxy monomer with dicyclo diacetal for high-performance. readily degradable thermosets. Eur. Polym. J. 2019, 117, 200-207. [CrossRef]

26. Tao, Y.Q.; Zhou, J.F.; Fang, L.X.; Wang, Y.Q.; Chen, X.Y.; Chen, X.R.; Hou, J.R.; Sun, J.; Fang, Q. Fluoro-containing Polysiloxane Thermoset with Good Thermostability and Acid Resistance Based on the Renewable Multifunctional Vanillin. ACS Sustain. Chem. Eng. 2019, 7, 7304-7311. [CrossRef]

27. Liu, F.; Cao, H.; Mao, Q.; Song, P.; Yang, H. Effects of monomer structure on the morphology of polymer networks and the electro-optical properties of polymer-dispersed liquid crystal films. Liq. Cryst. 2012, 39, 419-424. [CrossRef]

28. Elouali, F.Z.; Maschke, U. Effects of Monomer Structure on Morphology and Electro-Optical Properties of Polymer/Liquid Crystal Systems. Mol. Cryst. Liq. Cryst. 2011, 543, 107/[873]-116/[882]. [CrossRef]

29. Li, W.; Cao, Y.; Cao, H.; Kashima, M.; Kong, L.; Yang, H. Effects of the structures of polymerizable monomers on the electro-optical properties of UV cured polymer dispersed liquid crystal films. J. Polym. Sci. Part B Polym. Phys. 2008, 46, 1369-1375. [CrossRef]

30. Mialon, L.; Vanderhenst, R.; Pemba, A.G.; Miller, S.A. Polyalkylenehydroxybenzoates (PAHBs): Biorenewable aromatic/aliphatic polyesters from lignin. Macromol. Rapid Commun. 2011, 32, 1386-1392. [CrossRef]

31. Chen, Q.; Ren, T.; Chai, Y.; Guo, Y.; Ingram, I.D.V.; North, M.; Xie, H.; Kent Zhao, Z. Preparation of Novel Aromatic-Aliphatic Poly(ketone ester)s through Condensation of Biomass-Derived Monomers. ChemCatChem 2018, 10, 5377-5381. [CrossRef]

32. Teimuri-Mofrad, R.; Esmati, S.; Tahmasebi, S.; Gholamhosseini-Nazari, M. Bisferrocene-containing ionic liquid supported on silica coated Fe3O4: A novel nanomagnetic catalyst for the synthesis of dihydropyrano[2,3-c] coumarin derivatives. J. Organomet. Chem. 2018, 870, 38-50. [CrossRef]

33. Lee, I.; Yang, J.; Lee, J.H.; Choe, Y.S. Synthesis and evaluation of 1-(4-F-18 fluoroethyl)-7-(4'-methyl) curcumin with improved brain permeability for beta-amyloid plaque imaging. Bioorg. Med. Chem. Lett. 2011, 21, 5765-5769. [CrossRef]

34. Hoshi, Y.; Xu, Y.; Ober, C.K. Photo-cleavable anti-fouling polymer brushes: A simple and versatile platform for multicomponent protein patterning. Polymer 2013, 54, 1762-1767. [CrossRef]

35. Kitamura, T.; Inoue, Y.; Maeda, T.; Oyamada, J. Convenient synthesis of ethylene carbonates from carbon dioxide and 1,2-diols at atmospheric pressure of carbon dioxide. Synth. Commun. 2015, 46, 39-45. [CrossRef]

36. García, K.E.; Navarro, R.; Ramírez-Hernández, A.; Marcos-Fernández, Á. New routes to difunctional macroglycols using ethylene carbonate: Reaction with bis-(2-hydroxyethyl) terephthalate and degradation of poly(ethylene terephthalate). Polym. Degrad. Stab. 2017, 144, 195-206. [CrossRef]

37. Comerford, J.W.; Ingram, I.D.V.; North, M.; Wu, X. Sustainable metal-based catalysts for the synthesis of cyclic carbonates containing five-membered rings. Green Chem. 2015, 46, 1966-1987. [CrossRef]

38. Lippits, M.J.; Nieuwenhuys, B.E. Direct conversion of ethanol into ethylene oxide on copper and silver nanoparticles Effect of addition of CeOx and Li2O. Catal. Today 2010, 154, 127-132. [CrossRef]

39. Oulame, M.Z.; Pion, F.; Allauddin, S.; Raju, K.V.S.N.; Ducrot, P.-H.; Allais, F. Renewable alternating aliphatic-aromatic poly(ester-urethane)s prepared from ferulic acid and bio-based diols. Eur. Polym. J. 2015, 63, 186-193. [CrossRef]

40. Morales, M.; Ataman, M.; Badr, S.; Linster, S.; Kourlimpinis, I.; Papadokonstantakis, S.; Hatzimanikatis, V.; Hungerbuhler, K. Sustainability assessment of succinic acid production technologies from biomass using metabolic engineering. Energy Environ. Sci 2016, 9, 2794-2805. [CrossRef]

41. Yan, Y.; Siegwart, D.J. Scalable synthesis and derivation of functional polyesters bearing ene and epoxide side chains. Polym. Chem. 2014, 5, 1362-1371. [CrossRef]

42. Sousa, A.F.; Coelho, J.F.J.; Silvestre, A.J.D. Renewable-based poly((ether)ester)s from 2,5-furandicarboxylic acid. Polymer 2016, 98, 129-135. [CrossRef]

43. Hu, L.; He, A.Y.; Liu, X.Y.; Xia, J.; Xu, J.X.; Zhou, S.Y.; Xu, J.M. Biocatalytic Transformation of 5-Hydroxymethylfurfural into High-Value Derivatives: Recent Advances and Future Aspects. ACS Sustain. Chem. Eng. 2018, 6, 15915-15935. [CrossRef]

44. Wang, J.G.; Liu, X.Q.; Zhu, J. From Furan to High Quality Bio-based Poly(ethylene furandicarboxylate). Chin. J. Polym. Sci. 2018, 36, 720-727. [CrossRef] 
45. Gandini, A.; Coelho, D.; Gomes, M.; Reis, B.; Silvestre, A. Materials from renewable resources based on furan monomers and furan chemistry: Work in progress. J. Mater. Chem. 2009, 19, 8656-8664. [CrossRef]

46. De Vries, J.G. Green Syntheses of Heterocycles of Industrial Importance. 5-Hydroxymethylfurfural as a Platform Chemical. Adv. Heterocycl. Chem. 2017, 121, 247-293.

47. Mou, Z.; Chen, E.Y.X. Polyesters and Poly(ester-urethane)s from Biobased Difuranic Polyols. ACS Sustain. Chem. Eng. 2016, 4, 7118-7129. [CrossRef]

48. Genovese, L.; Lotti, N.; Siracusa, V.; Munari, A. Poly(Neopentyl Glycol Furanoate): A Member of the Furan-Based Polyester Family with Smart Barrier Performances for Sustainable Food Packaging Applications. Materials 2017, 10, 1028. [CrossRef]

49. Gomes, M.; Gandini, A.; Silvestre, A.J.D.; Reis, B. Synthesis and Characterization of Poly(2,5-furan dicarboxylate)s Based on a Variety of Diols. J. Polym. Sci. Pol. Chem. 2011, 49, 3759-3768. [CrossRef]

50. Mou, Z.; Feng, S.; Chen, E.Y.X. Bio-based difuranic polyol monomers and their derived linear and cross-linked polyurethanes. Polym. Chem. 2016, 7, 1593-1602. [CrossRef]

51. Jiang, N.; Li, G.F.; Zhang, B.H.; Zhu, D.X.; Su, Z.M.; Bryce, M.R. Aggregation-Induced Long-Lived Phosphorescence in Nonconjugated Polyurethane Derivatives at 77 K. Macromolecules 2018, 51, 4178-4184. [CrossRef]

52. Nguyen, L.T.T.; Devroede, J.; Plasschaert, K.; Jonckheere, L.; Haucourt, N.; Du Prez, F.E. Providing polyurethane foams with functionality: A kinetic comparison of different "click" and coupling reaction pathways. Polym. Chem. 2013, 4, 1546-1556. [CrossRef]

53. Garcia, D.E.; Glasser, W.G.; Pizzi, A.; Paczkowski, S.; Laborie, M.P. Hydroxypropyl tannin from Pinus pinaster bark as polyol source in urethane chemistry. Eur. Polym. J. 2015, 67, 152-165. [CrossRef]

54. Mahmood, N.; Yuan, Z.; Schmidt, J.; Xu, C. Preparation of bio-based rigid polyurethane foam using hydrolytically depolymerized Kraft lignin via direct replacement or oxypropylation. Eur. Polym. J. 2015, 68, 1-9. [CrossRef]

55. Chen, Q.; Gao, K.; Peng, C.; Xie, H.; Zhao, Z.K.; Bao, M. Preparation of lignin/glycerol-based bis(cyclic carbonate) for the synthesis of polyurethanes. Green Chem. 2015, 17, 4546-4551. [CrossRef]

56. Clark, J.H.; Farmer, T.J.; Ingram, I.D.V.; Lie, Y.; North, M. Renewable Self-Blowing Non-Isocyanate Polyurethane Foams from Lysine and Sorbitol. Eur. J. Org. Chem. 2018, 2018, 4265-4271. [CrossRef]

57. Hemingway, J.; Eskandari, M.; Rajcan, I. Genetic and Environmental Effects on Fatty Acid Composition in Soybeans with Potential Use in the Automotive Industry. Crop Sci. 2015, 55, 658-668. [CrossRef]

58. Caracciolo, P.C.; Buffa, F.; Abraham, G.A. Effect of the hard segment chemistry and structure on the thermal and mechanical properties of novel biomedical segmented poly(esterurethanes). J. Mater. Sci. Mater. Med. 2009, 20, 145-155. [CrossRef]

(C) 2020 by the authors. Licensee MDPI, Basel, Switzerland. This article is an open access article distributed under the terms and conditions of the Creative Commons Attribution (CC BY) license (http://creativecommons.org/licenses/by/4.0/). 